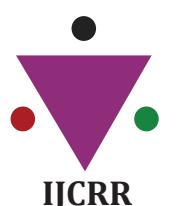

IJCRR

Section: Healthcare

Sci. Journal Impact

Factor: 5.385 (2017)

ICV: 71.54 (2015)

\title{
The Impact of Blindness on the Socio Economic Lives of Young Adults in South Western Nigeria
}

\section{Onabolu Oluwatoni 01, Jagun Omodele 02, Ebonhor Michael ${ }^{3}$}

'Department Of Surgery, Olabisi Onabanjo University Ago-lwoye, Ogun State, Nigeria; 'Department Of Surgery, Babcock University Ilishan-Remo, Ogun State, Nigeria; ${ }^{3}$ Federal Government College Odogbolu, Ogun State, Nigeria.

\section{ABSTRACT}

Background: Rehabilitation of the blind in developing countries is usually focused on education for employment purposes with little attention to social life. Yet it is known that the blind have dreams and aspiration that are dampened by their disability. This study examined how rehabilitated blind adults cope socially with their disability.

Methods: This was a cross sectional observational study amongst registered members of the Nigerian Association of the Blind, Ogun State Chapter. Sixty-six adults were recruited and subjected to a validated interviewer administered questionnaire.

Results: Age range was 17-68 years with mean of $38.51 \pm 11.97$ years. There were $42(63.7 \%)$ males and $36(54.5 \%)$ were married. Majority of those that were married $29(80 \%)$ had 3 children each and $35(53 \%)$ lived in rented/institutional apartments where they either partially or fully paid for rent. 25(37.88\%) participants had attained tertiary education. 50\% were self-employed and $19(28.8 \%)$ were engaged in competitive employment. $44.8 \%$ of the self- employed earned less than 19000 naira per month (\$52.6) while those in paid employment earned up to 72000 Naira per month (\$193.9).

Conclusion: Despite rehabilitation, the earning capacity of the blind adult is low. Blindness has a negative impact on social lives even after rehabilitation.

Key Words: Blind, Marriage, Social life, Economic Challenges

\section{INTRODUCTION}

Young adults with visual impairment wish for a bright and productive future but this dream is dampened by difficulties resulting from their visual disabilities ${ }^{1}$. One important barrier is the rate of competitive employment of the visually impaired and blind which had been found to be considerably lower than their sighted peers ${ }^{2}$. In Europe the visually impaired were at higher risk of not having a paid job, being unemployed, belonging to a manual social class, having less job satisfaction, and getting inadequate salary ${ }^{3,4}$.

Researchers have also shown that persons with visual impairment have distinct challenges Regarding relating with other people, mobility, mental and social wellbeing ${ }^{5}$. In Nigeria, most blind adults are seen as illiterate street beggars while others become dependent on sighted family members for daily living ${ }^{6}$. However a few get educated even up to tertiary level and become fully rehabilitated but they still have difficulty in securing paid employment ${ }^{7,8}$.

A longitudinal study on blind adolescents revealed that they have a small social network with fewer friends and are more likely to stay in familiar surroundings like their homes because of socializing difficulties ${ }^{9}$. Therefore dating the opposite sex is uncommon leading to late starting of a family ${ }^{9}$.

The prevalence of blindness in Ogun State of Nigeria was 2.8 $\%$ (Nigeria National Blindness Survey 2005-2007) ${ }^{10}$. There are two primary schools for the blind and three integrated secondary schools. Ogun state has a literacy rate of 78.8\% amongst adults and has a high concentration of industries ${ }^{11}$. The minimum civil service salary per month is N18000 (US $\$ 50)^{12}$.

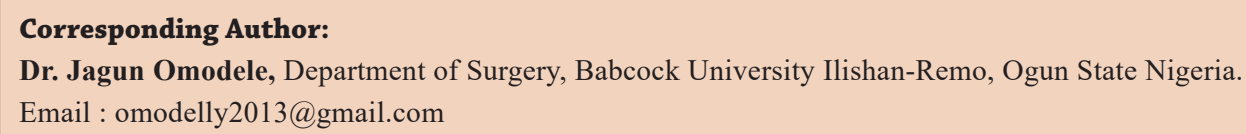


Transportation within the towns and villages is by road. Majority of the roads lack pedestrian pathways which makes mobility difficult for the visually impaired even with their canes. The purpose of this communication is to give information on the socioeconomic life of the rehabilitated blind and visually impaired in South West Nigeria so that special schools for rehabilitation can include mentorship, job placement and social interactions in their curriculum.

\section{MATERIALS AND METHODS}

Study design. This was a cross sectional observational study of the registered members of the Nigerian Association of the Blind (NAB), Ogun State chapter. Sample size consisted of 66 consenting participants from a sample frame of 206 registered members.

Each participant was subjected to an interviewer administered questionnaire (during their monthly meetings until all consenting members were covered) consisting of their biodata, education, occupation, income per month, accommodation, marital status and number of children. The questionnaire was initially validated amongst members of another branch of NAB in the adjacent State (Lagos) and adjusted accordingly. Ethical approval was obtained from The Olabisi Onabanjo University Teaching Hospital review committee. All participants gave Verbal consent and the Chairman of the NAB provided a written consent prior to the study.

Statistics: The result was recorded in a personal computer using Statistical Package for Social Sciences IBM version 21 spread sheets. Discrete variables were compared by means and percentages while continuous variables were compared using Pearson's chi- square with values $\leq 0.05$ as being significant and Fishers exact where the subjects were too few for chi-square.

\section{RESULTS}

The age range of participants was 17-68 years, mean $38.51 \pm 11.97$. There were Forty two $(63.66 \%)$ males. Fifty nine $(89.4 \%)$ were totally blind (Nil Perception of Light), five $(7.6 \%)$ had hand motion vision in the better eye, while two $(3 \%)$ had $1 / 60$ vision. All of them had at least primary school education. Twenty five (37.88\%) attended Colleges or Polytechnics. Thirty- three $(50 \%)$ were self-employed, $17(25.75 \%)$ were employed by Government, 2 work with a private companies while 9 were students. All Government employees were teachers in schools for the blind. Those that were self- employed, sold locally made soap, insecticides, fashionable bags and table mats self-made locally. Twenty three $(44.8 \%)$ of the participants, who were self- employed earned between 10000 and 19000 naira per month (\$27.7-
\$52.6) whereas the Government employees earned between 18,000 and 35,000 naira per month (\$49.9-\$97) Table I. Two of them were street beggars and could not ascertain their monthly income. Thirty six $(54.5 \%)$ were married $(25$ males), twenty-seven (40.9\%) were single, two were widowed while one was divorced (Table II). Fourteen single participants $(21.2 \%)$ were between 30 and 49 years old. Twelve $(70.5 \%)$ out of seventeen Government employees and 17 out of $32(53 \%)$ self-employed participants were married (Table III). 13 men and 5 women were noted to be married to sighted spouses but the difference was not statistically significant.

Majority of those that were married 29 (80\%) had 3 children or less. Thirty five (53\%) lived in rented apartments, eighteen of which had to seek assistance to pay their rents. It was noted that the blind participants had difficulties in getting houses to rent in the community because landlords were skeptical about cleaning and regular rent payments. Those that were competitively employed were relatively more comfortably accommodated than those without jobs. Seven out of seventeen (41\%) Government employees and 11 out of 35 (31\%) self-employed participants lived in their own houses. Participants also indicated restrictions in social party event attendance which is a regular past time of individuals of the study community, as they usually have to attend in groups and less frequently with their partners. Most of their social events were restricted to organized meetings convened by the association. Table IV shows how regular earning contributed to the social status in this study

\section{DISCUSSION}

The importance of education and rehabilitation in the lives of the visually impaired and blind have been emphasized in several studies ${ }^{2,13,14}$. Education and rehabilitation should increase the Chance of gainful employment for the visually impaired and blind individuals ${ }^{2}$. In this study only $28.8 \%$ were competitively employed, majority of whom were government workers. This was less than $37 \%$ in Bell's study in the United States and $64 \%$ of Harrabi et al during a global survey ${ }^{15}$. The rate of competitive employment is lower in this study because employers were most likely ignorant of the capabilities of the educated blind ${ }^{7}$ and also because the major workplaces found in this community are factories and might not be conducive for the visually disabled to work in as also documented in New Zealand ${ }^{16}$. Other barriers for employment were poor mobility in a rough terrain and poor transportation network ${ }^{7}$. Although blind employed workers were paid same salary as their peers, the choice of jobs was limited to teaching blind students thus supporting the study of MojonAzzi et $\mathrm{al}^{3}$ who found that there was limited freedom for the blind to decide on their type of job. Those that were self- employed depended on hand-crafts and cheap household goods which could barely sustain them. While employed Govern- 
ment workers earned regular and relatively more salary, the earnings of the self-employed was not regular and some of them could not ascertain their monthly incomes.

The participants that lived in their own houses were elderly and many of them had gotten the property before they became blind. Young participants ( $<40$ years) could hardly pay their house rents without assistance. These younger people became blind as children and teenagers, and so did not enjoy economic freedom like their older counterparts.

In this study, participants married late supporting the findings of Gold et $\mathrm{al}^{9}$ as many of our subjects in their productive years were still single which could portray difficulty in developing romantic relationship ${ }^{17}$. Previous studies had shown that blind people led sedentary lives which are a hindrance to socializing and mixing with the opposite $\operatorname{sex}^{18}$ and that they frequently went out in groups probably due to low selfesteem $^{19}$. Our participants were more likely to meet in their schools and at regular organized meetings than during sport activities in contrast with young sighted people. Rehabilitation services in developing countries are usually focused on mobility, daily living skills and employment leaving out social life which is an integral part of living ${ }^{20}$. Social events could be arranged as part of their training in rehabilitation so as to encourage social interaction with mentoring. Successful blind adults can also mentor younger ones during the rehabilitation programs. Studies in Canada have shown that social skills can be learnt through various interactions and via mentoring ${ }^{1,19}$.

This study showed that blind men were more likely to marry sighted women than for sighted men to marry blind women especially when they are both young. This may be because it is difficult in the African culture to see blind women as house keepers. Blind people in this study however gave poverty and their physical challenge as the main reasons for late marriages and for marrying blind people like themselves.

\section{CONCLUSION}

Blindness has a negative impact on the economic and social life of people. Education and rehabilitation did not always translate to employment in developing countries. It would seem that visually impaired people especially the blind need more assistance for improvement in their social lives.

\section{ACKNOWLEDGEMENT}

We acknowledge the immense help received from the scholars whose articles are cited and included in references of this manuscript.

\section{Conflict of interest: None}

External source of funding: None, funded by the researchers.

\section{REFERENCES}

1. Heppe EC, Kef S, Schuengel C. Testing the effectiveness of a mentoring intervention to improve social participation of adolescents with visual impairments : study protocol for a randomized controlled trial. Trials 2015;16:1-11.

2. Bell E. Competitive employment for consumers who are legally blind: A 10-year retrospective study. J Rehabil Res Dev [Internet] 2010; 47(2):109-16.

3. Mojon-azzi SM, Sousa-poza A, Mojon DS. Impact of Low Vision on Employment 2010;381-8.

4. Ulldemolins AR, Lansingh VC, Valencia LG, Carter MJ, Eckert KA. Review Article Social inequalities in blindness and visual impairment: A review of social determinants. Indian Journal Ophthalmol 2012;60(5):368-375.

5. Elsman EBM, Van Rens GHMB, Van Nispen RMA. Impact of visual impairment on the lives of young adults in the Netherlands : a concept-mapping approach. Disability and Rehabilitation 2017; 39(26):2607-18.

6. Ademola-Popoola D, Tunde-Ayinmode M, Akande T. Psychosocial characteristics of totally blind people in a Nigerian city. Middle East Afr J Ophthalmol [Internet]. 2010;17(4):335.

7. Onabolu OO, Bodunde OT, Ajibode HA, Otulana TO, Daniel OJ, Ebonhor ME. Rehabilitation and Paid Employment for Blind People in a Low Income Country. J Adv Med Med Res. 2018;25(8):1-9.

8. Wolffe KE, Ajuwon PM, Kelly SM. Working with Visual Impairment in Nigeria: A Qualitative Look at Employment Status. J Vis Impair Blind [Internet]. 2013;107(6):425-36.

9. Gold D, Shaw A, Wolffe K. The social lives of Canadian youths with visual impairments. J Vis Impair Blind. 2010;104(7):43143.

10. Rabiu MM, Kyari F, Ezelum C, Elhassan E, Sanda S, Gudlavalleti V. S et al. Review of the publications of the Nigeria national blindness survey: Methodology, prevalence, causes of blindness and visual impairment and outcome of cataract surgery. Ann Afr Med. 2012;11(3):125-30.

11. Ogun State : Ogun State.gov.ng/ogun state 2018. (Accessed 30/04/2019)

12. Nigeria: Minimum wage https://nass.gov.ng/document/download/. (Accessed 30/04/2019).

13. Lindsay S, McDougalL C, Menna-Dack D., Sandford R. An ecological approach to understanding barriers to employment for youth with disabilities compared to their typically developing peers : Views of youth, employers, and job counselors. Disabil Rehabil. 2015;37 (8):701-11.

14. Lee IS, Park SK. Employment Status and Predictors among People with Visual Impairments in South Korea: Results of a National Survey. Journal of Visual impairment \& Blindness 2008; 102(3):147-159.

15. Harrabi H, Aubin M, Zunzunegui MV, Haddad S, Freeman EE. Visual Difficulty and Employment Status in the World. 2014;9(2):1-6.

16. Grow SJ, Daye P. Barriers to Employment Identified by Blind and Vision-Impaired Persons in New Zealand. Soc Policy J New Zeal. 2005;(26):173-85.

17. Pfeiffer JP and Pinquart M. Attainment of developmental tasks by adolescents with visual impairment Journal ofVisual Impairment \& Blindness 2011;3:3-44. 
18. Law M. Participation in the occupation of everyday life. Am J Occup Ther 2002;56(6):640-9.

19. Salehi M, Azarbevejani A, Shafiei K, Ziaei T, Shayegh B. Selfesteem, general and sexual concepts in blind people. J. Res Med Sci 2015;20(10):930-60.
20. Van LL, Rainey L, Kef S, Van RG, Van NR. Investigating rehabilitation needsof visually impaired young adults according to the international classification of functioning disability and health. Acta Ophthalmologica 2015;93(7).

Table I: Monthly income of rehabilitated blind adults in Ogun State

\begin{tabular}{lcc}
\hline INCOME (Naira) & NUMBER OF PARTICIPANTS & $\%$ \\
\hline$<$ 10000 & 5 & 7.6 \\
10000-1900o & 12 & 18.2 \\
$20000-29000$ & 11 & 16.7 \\
$30000-39000$ & 7 & 10.6 \\
$40000-49000$ & 7 & 10.6 \\
$50000-59000$ & 1 & 1.5 \\
$60000-69000$ & 1 & 1.5 \\
$>$ 7000o & 3 & 4.5 \\
Not Known & 19 & 29.0 \\
TOTAL & 66 & 100 \\
\hline
\end{tabular}

Table II: Age group and marital status of participants

\begin{tabular}{lccccc} 
& MARRIED & SINGLE & WIDOWED & SEPERATED & TOTAL \\
AGE GROUP & & & & & \\
$10-19$ & 0 & 3 & 0 & 0 & 3 \\
$20-29$ & 3 & 10 & 0 & 0 & 13 \\
$30-39$ & 11 & 10 & 0 & 0 & 21 \\
$40-49$ & 13 & 4 & 2 & 0 & 18 \\
$50-59$ & 5 & 0 & 0 & 0 & 7 \\
$\geq 60$ & 4 & 0 & 2 & 1 & 66 \\
TOTAL & 36 & 27 & & & 0 \\
\hline
\end{tabular}

Table III: Marital status and type of employment of participants

\begin{tabular}{lcccccc} 
& $\begin{array}{c}\text { EMPLOYMENT } \\
\text { TYPES } \\
\text { Self employment }\end{array}$ & $\begin{array}{c}\text { TOTAL } \\
\text { Government } \\
\text { employment }\end{array}$ & Other employment & Unemployed & Student \\
MARITAL STATUS & 17 & 12 & 2 & & & \\
Married & 13 & 4 & 0 & 2 & 1 & 36 \\
Single & 2 & 0 & 0 & 0 & 0 & 27 \\
Widowed & 0 & 1 & 0 & 0 & 0 & 2 \\
Separated & 32 & 17 & 2 & 6 & 9 & 66 \\
TOTAL & & & & & & 0 \\
\hline
\end{tabular}


Table IV: Employment status of participants with types of living accommodation

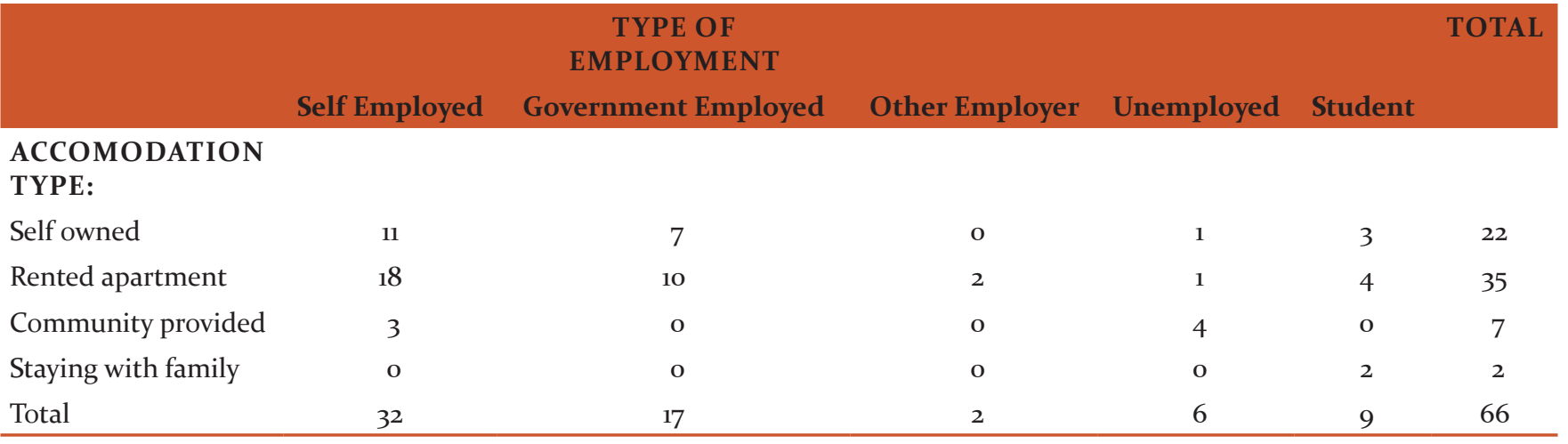

